\title{
Modernidade e tradiçóes intelectuais entre Porto Alegre e o Rio de Janeiro nas primeiras décadas do século XX
}

\author{
Cássia Daiane Macedo da Silveira ${ }^{1^{*}}$
}

${ }^{1}$ Universidade Federal do Rio Grande do Sul. Porto Alegre/RS — Brasil

\section{RESUMO}

Neste artigo ${ }^{1}$ aborda-se a tradição literária do decadentismo. A análise se centra em dois grupos de escritores do Rio Grande do Sul e procura rastrear a formação e a adesão a essa tradiçấo literária. O objetivo primordial foi caracterizar os escritos dos dois grupos de autores analisados, buscando enfatizar aquilo que os unificava enquanto grupo. Entende-se que, com a forte tradição crítica estabelecida a partir do modernismo, inúmeras outras formas de narrar a modernidade acabaram esquecidas. Assim, também se tem a intenção de recuperar os modos narrativos e as culturas estéticas existentes no Brasil antes do período modernista, enfocando a constante mobilidade das culturas literárias, que vieram a configurar uma cultura literária centralizada no Rio de Janeiro capaz de abrigar elementos de várias partes do país.

Palavras-chave: modernismo; tradições literárias; decadentismo.

\section{Modernity and intellectual traditions in Porto Alegre and Rio de Janeiro during the first decades of the twentieth century}

\begin{abstract}
This article discusses the literary tradition of decadentism. It focuses on two groups of writers from Rio Grande do Sul and tracks the formation of decadentism among them and their adherence to it. The major aim of this study is to characterize the writings of both groups of authors, emphasizing what unifies them. Since many ways of narrating modernity were forgotten since the establishment of the strong critical traditions associated
\end{abstract}

DOI: http://dx.doi.org/10.1590/2237-101X02104409

Artigo recebido em 19 de dezembro de 2018 e aceito para publicação em 20 de julho de 2019.

* Professora da Universidade Federal do Rio Grande do Sul / Departamento de História, Porto Alegre/RS Brasil. E-mail: cassiamsilveira@gmail.com. ORCID: https://orcid.org/0000-0002-3390-6015.

${ }^{1} \mathrm{O}$ presente artigo é fruto de análises realizadas para conclusão de minha tese de doutorado, defendida na Universidade Estadual de Campinas, financiada pela CAPES e pelo CNPq. 
with modernism, this study also aims to recover narrative modes and aesthetic cultures presents in Brazil before modernist period, such as decadentism. The constant mobility of these separate literary cultures eventually came together to form a unified literary culture in Rio de Janeiro capable of sheltering elements from several parts of the country.

Keywords: modernism; literary traditions; decadentism.

\section{Modernidad y tradiciones intelectuales entre Porto Alegre y Río de Janeiro en las primeras décadas del siglo XX}

\section{RESUMEN}

En este artículo se aborda la tradición literaria del decadentismo. El análisis se centra em dos grupos de escritores de Río Grande del Sur y se procura rastrear la formación y la adhesión a esta tradición literaria. El objetivo primordial fue caracterizar los escritos de los dos grupos de autores analizados, buscando enfatizar aquello que los unificaba como grupo. Se entiende que; con la fuerte tradición crítica establecida a partir del modernismo, innúmeras otras formas de narrar la modernidad acabaron siendo olvidadas. Así, también se tiene la intención de recuperar los modos narrativos y las culturas estéticas existentes en Brasil antes del período modernista, enfocando la constante movilidad de las culturas literarias, que vinieron a configurar una cultura literaria centralizada en Río de Janeiro, capaz de abrigar elementos de varias partes del país.

Palabras clave: modernismo; tradiciones literarias; decadentismo.

I.

No primeiro ano do século XX, era publicado em Porto Alegre, pelas oficinas tipográficas do Correio do Povo, um romance acerca de um certo letrado porto-alegrense. Era o Juca, o letrado, de autoria de Zeferino Brazil. Consta que este havia sido publicado anteriormente no Jornal do Comércio, também de Porto Alegre, ainda no ano de 1896. Embora o livro tenha gerado muito debate, em torno sobretudo da identidade "verdadeira" de Juca, o próprio autor afirmava, à época, que a personagem não era "um indivíduo", mas "a encarnação de muitos indivíduos" (BRAZIL, 1975 [1900], p. 8), o que, aliás, dava os contornos de seus propósitos de elaboração de um romance experimental, como aquele que propunha Zola, situado no Sul do Brasil. É dessa obra que partimos para refletir sobre as manifestaçóes decadentes no Rio Grande do Sul, uma das tantas tradiçóes que antecedeu a literatura modernista no Brasil na sua forma de pensar o mundo moderno. Além desse livro, trataremos 
também de outras obras de Zeferino Brazil e do autor Marcelo Gama, seu contemporâneo, e de algumas das composiçóes de poetas do chamado "grupo da Praça da Misericórdia”, de Porto Alegre, que podem ser considerados de uma geração literária posterior àquela de Brazil e de Gama. Por meio dessas duas geraçóes literárias rio-grandenses, procuramos compreender as adesôes culturais e seus deslocamentos como uma tentativa, empreendida por esses escritores, de narrar as transformaçóes pelas quais passava o mundo moderno.

Já há algum tempo, a historiografia vem revisando a suposta centralidade da vanguarda futurista paulista na trajetória do modernismo brasileiro, deslocando o cerne da reflexão para a própria historicidade de uma tal elaboração: assim, a Semana de 22, como marco cronológico para o modernismo brasileiro (que também constitui um pré e um pós-modernismo), seria uma construção das próprias vanguardas paulistas, "que a atualizaram ao longo das décadas de 1930 e 1950" (VELLOSO, 2010). Tal deslocamento abre espaço para a análise de muitas outras formas de expressar o moderno, dentre as quais, por exemplo, o modernismo carioca (LINS, 2010, p. 29; VELLOSO, 1996; GOMES, 1999). Angela de Castro Gomes (1999) estudou algumas manifestaçôes modernistas daqueles que designou como "intelectuais cariocas", ou seja, "os que viviam e teciam suas redes de sociabilidade na cidade do Rio de Janeiro". Entretanto, basta uma rápida observaçấo dos indivíduos que constituíam esse grupo para verificarmos a imensa abrangência geográfica de suas origens regionais: embora sediados por certo tempo no Rio de Janeiro, então capital da República, esses escritores advinham de estados diferentes e traziam consigo, quando chegavam ao Rio, uma herança de amizades, tradiçóes e modos de escrita das quais não se desfaziam apenas pelo deslocamento espacial. Alguns dos escritores analisados por Gomes em sua obra pertenciam justamente ao já referido grupo da Praça da Misericórdia. Nesse sentido, cabe, ainda, refletirmos acerca das múltiplas tradiçóes intelectuais que convergiam para o Rio de Janeiro, configurando uma estética necessariamente variada também em suas raízes. No entanto, a reflexão sobre tais tradiçôes que criaram formas de narrar o moderno pode ser realizada sem partir das mesmas concepçóes essencialistas sobre a história literária, que configuram um pré e um pós-modernismo, ou que veem no modernismo o seu próprio início e fim. Essas tradiçôes devem ser buscadas em suas historicidades, é o que defendemos aqui.

Os modos pelos quais analisaremos o decadentismo, portanto, partem da reflexão de Raymond Williams a respeito daqueles grupos culturais que se tornam difíceis de serem estudados em função do pequeno número de seus integrantes e/ou da fluidez de suas instituiçóes e de seus princípios, e que são frequentemente definidos pela amizade entre seus membros. Em razão disso, Williams propóe que tais grupos têm em comum "um corpo de práticas ou um ethos que os distinguem, ao invés de princípios ou objetivos definidos em um manifesto" (WILLIAMS, 1999, p. 140). Esse modo de pensar os grupos literários, acreditamos, é bastante propício no sentido de recuperar a concretude dos próprios sujeitos históricos, nas suas decisões e indecisôes, nos caminhos que escolheram dentre as possibili- 
dades que se lhes apresentaram. São nessas práticas que encontramos suas adesôes e recusas e é a partir disso que podemos defini-los sem a antecipação de conceitos preestabelecidos de modernismo ou pré-modernismo.

Não nos resta dúvida da grande quantidade de críticos e historiadores da literatura que se preocupou em tentar conceituar a literatura modernista e aquilo que a precedeu (BRADBURY; McFARLANE, 1998; CALINESCU, 1991; RAINEY, 1998; SOMIGLI, 2003; GLUCK, 2005; GAY, 2009; LEHAN, 2009; BUTLER, 2010; SCHOLES; WULFMAN, 2010), sendo esta ora caracterizada sobretudo por movimentos de vanguarda, ora entendida como um processo de sistemática ruptura com certas concepçóes românticas, mesmo quando mantendo algumas de suas convençôes. É mais ou menos consensual, contudo, que seu início tenha se dado entre o final do século XIX e o começo do século XX, embora com relação a seu término haja bem menos acordo. Também parece largamente aceita sua intrínseca associação com a modernidade, uma vez que o desenvolvimento tecnológico e industrial e o crescimento das cidades seriam associados ao campo de possibilidades de surgimento da literatura modernista, que apresentaria respostas a essas transformaçôes sociais e econômicas. Mudanças nos esquemas de pensamento, como a possibilidade de se pensar como parte de um universo não mais operado por uma divindade, também são apontadas como fatores associados ao surgimento do modernismo na Europa e nos Estados Unidos (CALINESCU, 1991, p. 51; BRADBURY; McFARLANE, p. 76-82; LEHAN, 2009. p. 7-8).

Os estudiosos que se dedicaram a pensar tais concepçôes de literatura modernista, contudo, raramente incluíram em suas reflexóes os modernismos latino-americanos, talvez porque estes eram pouco associados às grandes cidades dos centros economicamente desenvolvidos do mundo. Dessa forma, encontramos, a esse respeito, aquelas definiçóes advindas de países centrais, tidas por universais, e aquelas definiçôes que buscam as especificidades nacionais, periféricas, nas quais se inclui a bibliografia acerca do modernismo brasileiro, por exemplo. Além disso, a perspectiva de criar uma definição que incluísse também o modernismo de Rubén Darío, situando-o em dado lugar nesses movimentos literários globais, talvez tenha assustado alguns pesquisadores. Para Matei Calinescu (1991), contudo, foi Darío o primeiro a utilizar o termo "modernismo" associado a um movimento de renovação estética, em princípios da década de 1890. Segundo o crítico literário romeno, o modernismo de Darío se valia de inovaçôes estéticas francesas de fins do século XIX com nítido sentido de independência cultural em relação à autoridade da Espanha nesse campo. Enquanto na França, decadentes, parnasianos, simbolistas e outros se empenhavam em disputas paroquiais insípidas, na América Latina essas correntes se reuniam em algo que Calinescu considerou mais do que uma simples variante do simbolismo francês:

Ainda que o modernismo hispano-americano seja considerado frequentemente como uma variedade do simbolismo francês, seria muito mais correto dizer que constitui uma síntese de 
todas as principais tendências inovadoras que se manifestaram na França de finais do século XIX. O fato é que a vida literária francesa deste período estava dividida em uma variedade de escolas em conflito, movimentos, ou inclusive seitas [...] que, em seus esforços por estabelecer-se como entidades diferentes, não se deram conta do que tinham realmente em comum. Era muito mais fácil perceber este elemento comum desde uma perspectiva externa, e isto é exatamente o que lograram fazer os modernistas. Como estrangeiros, ainda que muitos deles tenham passado longos períodos na França, estavam separados do clima de rivalidade grupal e das mesquinhas polêmicas que prevaleciam na vida intelectual parisiense do momento, e eram capazes de penetrar além das meras aparências de diferença para compreender o espírito subjacente de renovação radical, que promoveram sob o nome de modernismo (CALINESCU, 1991., p. 77). ${ }^{2}$

Assim, o que Calinescu nos adverte diz respeito à imensa diversidade de contextos sociais e culturais que possibilitam o desenvolvimento e a compreensão de movimentos literários e de suas denominaçóes, bem como as muitas variantes das formas de perceber e de narrar as transformaçóes modernas, mesmo antes das profundas rupturas provocadas pela literatura modernista propriamente dita. Ainda em relação ao modernismo latino-americano de Rubén Darío, Mariano Siskind (2016) elabora a noção de “desejo de mundo", como um anseio cosmopolita vinculado a toda uma crítica à dependência cultural. Segundo o autor, é justamente a fim de estabelecer

uma cultura moderna ali onde, para eles, não havia nada, [que] os modernistas assumiram a tarefa da modernização estética e cultural confiantes na onipotência de sua sensibilidade contemporânea. O que para eles era moderno em uma América Latina que carecia de modernidade era seu próprio desejo moderno, muito em sincronia com o que imaginavam era a universalidade do modernismo europeu (SISKIND, 2016, p. 151). ${ }^{3}$

O que Siskind quer dizer é que, muito embora carentes de uma modernidade nos moldes europeus, os intelectuais latino-americanos vinculavam à ideia de uma literatura mundial,

\footnotetext{
${ }^{2}$ Todas os trechos em língua estrangeira tiveram tradução livre da autora. No original: "Aunque el modernismo hispano se considera a menudo como una variedad del simbolismo francés, sería mucho más correcto decir que constituye una síntesis de todas las principales tendencias innovadoras que se manifestaron en la Francia de finales del siglo XIX. El hecho es que la vida literaria francesa de este período estaba dividida en una variedad de escuelas en conflicto, movimientos, o incluso sectas ('Parnasse', 'décadisme', 'symbolime', 'école romane' etc.) que, en sus esfuerzos por establecerse como entidades diferentes, no se dieron cuenta de lo que tenían realmente en común. Era mucho más fácil percibir este elemento en común desde una perspectiva externa, y esto es exactamente lo que lograron hacer los modernistas".

${ }^{3}$ No original: "[...] una cultura moderna allí donde, para ellos, no había nada, los modernistas asumieron la tarea de la modernización estética y cultural confiados en la omnipotencia de su sensibilidad contemporánea. Lo que para ellos era moderno en una América Latina que carecía de modernidad era su propio deseo moderno, muy en sincronía con lo que imaginaban era la universalidad del modernismo europeo". O autor refere-se aos modernistas latino-americanos.
} 
cosmopolita, a possibilidade de tornar concretos seus desejos modernos. Antes mesmo da estética propriamente modernista vigorar, portanto, o desejo moderno, atrelado a uma literatura denominada cosmopolita, já existia naquelas incontáveis tradiçôes literárias e intelectuais. Nesse mesmo sentido podemos pensar também o caso específico do modernismo brasileiro, não como uma expressão certeiramente datada do percurso de uma vanguarda futurista paulista, mas como um gradual processo de adesão a valores e referências ligados ao que consideravam uma vida mais cosmopolita. Ou seja, defendemos que uma das tradiçóes que antecedeu o modernismo e que a ele se vinculou, no caso brasileiro, estava ligada a toda literatura de perfil cosmopolita em sua estética, em seus valores, e que possibilitou uma ruptura com aquela de traços românticos. Ainda de acordo com Siskind (2016, p. 152),

a literatura mundial seria uma constelação de discursos que invocam um mundo de literaturas, imprecisamente definido por uma noção abstrata de universalidade, marcada por sua abertura para receber literaturas marginais e por sua disponibilidade para que os modernistas [referese ao modernismo de Darío] inscrevam ali a especificidade estético-política de seus desejos modernos. O mundial como a postulação de um espaço e um corpus literários definidos por sua exterioridade em relaçâo à América Latina; um mundo literário que os escritores da regiāo imaginam como um reservatório universal de estéticas modernas/modernistas onde os cosmopolitas marginais encontram recursos retóricos e tópicos para articular uma modernização cultural não particularista. ${ }^{4}$

Ou seja, cabe-nos compreender como os diferentes grupos de literatos, em diferentes contextos socioculturais, informados pelas mais variadas tradiçóes e influências puderam expressar a modernidade, ou aquilo que percebiam como moderno, mesmo antes da estética modernista. Assim, buscar os percursos dos literatos que estudamos e as referências das quais se valiam, seu conjunto de valores, seu ethos, afinal, torna-se uma alternativa mais aproximada ao que eles próprios tentavam elaborar esteticamente, além de proporcionar uma perspectiva mais aberta a outras percepçôes do moderno, mais afinada com o que cada época e espaço produziu. Propomos compreender uma dessas tradiçôes literárias "cosmopolitas" e a adesão a ela no Rio Grande do Sul, a partir dos escritos de alguns dos representantes de dois grupos de escritores gaúchos.

\footnotetext{
${ }^{4}$ No original: “[...] la literatura mundial sería una constelación de discursos que invocan un mundo de literaturas, imprecisamente definido por una noción abstracta de universalidad, marcada por su apertura para recibir literaturas marginales y por su disponibilidad para que los modernistas inscriban allí la especificidad estético-política de sus deseos modernos. Lo mundial como la postulación de un espacio y un corpus literarios definidos por su exterioridad respecto de América Latina; un mundo literario que los escritores de la región imaginan como un reservatorio universal de estéticas modernas/modernistas donde los cosmopolitas marginales encuentran recursos retóricos y tópicos para articular una modernización cultural no particularista”.
} 
Na Porto Alegre fictícia criada por Zeferino Brazil, Juca se havia rebelado "contra a velha escola romântica e criara, no jornalismo provinciano, a crônica leve, bulhenta, feita num estilo trabalhado e puro, e onde o paradoxo espanta-burguês rufava como um tambor espalhafatoso e guerreiro" (BRAZIL, 1975 [1900], p. 9). Ele aparece no texto como alguém que se posicionava "contra o romantismo pulha e o verso choroso" (p. 10), e costumava bradar frases de efeito: "Não percam a tabaqueira da vovó Musa Antiga!" 5 É assim que Brazil caracteriza a personagem como um literato típico, um pouco nojento, cheio de caspa e com pouco talento demonstrado, apesar da imensa retórica em torno de si mesmo. Sempre às voltas com suas pilhas de jornais cariocas, "esmagado de spleen" e "morto de tédio", Juca tinha mais oratória do que publicações.

Muito embora Juca seja o protagonista, o modo como se dá a sua construção ao longo de todo o romance nos faz pensar que Brazil projetou certo antagonismo entre o estilo dessa personagem e o de outro letrado ficcional, Alberto. Enquanto aquele jamais havia de fato publicado qualquer coisa de fôlego, apenas textos curtos em jornais, destacando-se sobretudo pela retórica e pela crítica mordaz, este outro aparece como o literato dedicado, cujo ofício é bem mais laborioso, e que, a despeito de não ter arroubos de gênio, como Juca, apresenta produção mais regular e equilibrada. O que os unifica, ao fim e ao cabo, são os locais que frequentam: cafés e restaurantes nos quais se reuniam para beber e comer e onde a presença feminina é aceita, mas apenas dentro de um regime muito restrito. Esses ambientes também são frequentados, no romance, por uma "roda boêmia" repleta de outros personagens que habitam a redação de jornais e outros locais de reputação mais suspeita: o Almeidinha, da Folha Moderna, o Artur Taveira, "um polemista à Rochefort, também da redação da Folha, e que era muito mais conhecido pelos seus misteriosos rendez-vous com damas veladas do que pelo seu talento" (BRAZIL, 1975 [1900], p. 49). As reunióes descritas na obra sugerem certos padróes de amizade masculina que, embora fictícios, provavelmente guardavam semelhança com os padrôes culturais da época e do meio letrado.

A boêmia constituiu-se de um fenômeno social definido fortemente por um estilo de vida próprio, cujas primeiras referências remontam à França entre as décadas de 1830 e de 1840. É um fenômeno típico da modernidade que se formou, de acordo com Seigel (1986, p. 19), em contraste com o modo de vida burguês, naqueles aspectos ainda não disciplinados por este. Para Pierre Bourdieu, a invençáo do estilo de vida boêmio de fato veio como um contraponto ao estilo de vida burguês, tendo trazido "uma contribuição importante à inven-

\footnotetext{
${ }^{5}$ Alguns anos após a criação de seu personagem, Brazil publicava, ele próprio, o livro Vovó Musa, de versos, o qual continha um poema intitulado "Aos da velha escola", dedicado a Aquiles Porto Alegre, literato rio-grandense nascido em 1848 e que compunha a antiga geração romântica do estado.
} 
ção do estilo de vida do artista, com a fantasia, o trocadilho, a blague, as cançôes, a bebida e o amor sob todas as suas formas" (1996, p. 72).

$\mathrm{Na}$ cidade de Porto Alegre, também circulavam algumas noçôes do que seria o modo de vida do boêmio, sempre associado ao modo de vida do artista. Arthur Pinto da Rocha, por exemplo, professor da Faculdade de Direito de Porto Alegre, referia-se da seguinte forma ao artista Libindo Ferraz, no começo do século XX: "Libindo Ferraz é uma das organizações mais completas que temos conhecido de artista. Não lhe falta talento [...] mas... não tem constância nem persistência. [...] É um boêmio no sentido artístico do vocábulo...” (ROCHA apud SCARINCINI, 1982, p. 22). Assim, o estilo de vida boêmio figurava na cidade como uma forma possível de viver a vida de um artista: a frequência a bares e cafés, o convívio predominantemente masculino, as polêmicas, os encontros sinuosos com damas misteriosas, a crítica ao estilo de vida da burguesia, o comportamento desregrado, tudo isso aparece na Porto Alegre fictícia de Zeferino Brazil. Talvez possamos pensar essas práticas boêmias, ficcionais e efetivamente vividas, como a invenção, surgida em meados do século XIX na Europa, mas apropriada em diversas partes do globo, de uma nova forma de vivenciar a amizade masculina.

Marcelo Gama, poeta rio-grandense contemporâneo de Zeferino Brazil, também associa o modo de vida que podemos caracterizar como boêmio com o modo de vida do artista em sua poesia "Eu":

Sou imberbe, indolente e nem sempre ando limpo...

- um tipo de imbecil, grotesco e extravagante...

Mas, se engasto um bom verso, uma rima cantante,

Quase me sinto um deus, de tanto orgulho eu impo!

$[\ldots]$

Hostilizo o burguês, mas confesso, entretanto,

que acho um belo ideal o da vida burguesa:

Ter dinheiro, conforto, amigos, boa mesa,

e bocejar ouvindo as misérias que eu canto!...

(GAMA, 1902.s/p.)

A caracterizaçáo do artista, contudo, excedia, muitas vezes, aspectos relacionados ao comportamento. Também havia, no caso do romance Juca, o letrado, algumas prescriçôes mais propriamente literárias, autores e obras, estilos de narrativa, que eram considerados mais "sérios" e de melhor reputaçáo, e autores, obras e estilos "ultrapassados" e desejáveis apenas para a leitura das moças. No segundo capítulo do romance, Etelvina, uma moça que a tia de Juca havia adotado, entra em seu quarto para pedir um romance emprestado. Juca prontamente lhe oferece uma série de títulos ligados ao romantismo, como $A$ pata da gazela 
e A moreninha. Etelvina, revoltada, afirma, por sua vez, que deseja ler uma obra de arte, um "livro moderno, um livro de artista, um livro de nervo e de gênio" e pergunta a Juca se ele por acaso não tinha em sua biblioteca Flaubert, Goncourt, Gautier, Maupassant, Daudet, Bourget ou Loti (BRAZIL, 1975 [1900], p. 24). Etelvina deseja ler algo como Salammbô, Madame Bovary, Maison d'un artiste, Mensages, Soeur Philoméne (p. 25). O Juca, surpreso,

arrastou-a, nervoso, para o outro lado da sala, onde estava um armário envidraçado. Abriu-o com religioso respeito e mostrou-lhe, com dignidade, os seus homens. Eis aqui Flaubert, Salammbô, Madame Bovary, Tentation de Saint-Antoine, Bouvard et Pecuchet, a última e extraordinária obra do grande artista; estes são os Goncourt: Maison d’un artiste, o mais requintado e mais artístico livro dos incomparáveis irmãos, Soeur Philoméne, Charles Demailly; este agora é Maupassant: Pierre et Juan, Fort comme la mort, Norte coeur, L’unitile beauté; eis o fino e almiscarado orientalista Loti; o nevrótico e sensual Gautier, amigo das mulheres e do ópio; estes são os meus poetas, os poucos que eu tolero: Baudelaire, Leconte de Lisle, Richepin, Rolinai, Verlaine e Merimée (p. 25).

A lista de autores apresentada como sendo de "artistas modernos" são aqueles ligados de alguma forma à boêmia ou a uma renovação estética que rompe com o romantismo. O amálgama é esse rompimento, mas há ainda uma transformação no modo como cada um deles se apresenta como artista. O Juca conclui a exposiçấo de seus escritores favoritos deixando Etelvina livre para acessar a estante envidraçada dos escritores modernos, mas faz uma intrigante recomendação: "proíbo-te que toques nos volumes da última prateleira: são de Zola, e... não convém...” (p. 26). Os mesmos autores inspiravam Juca na sua criação, um romance que desejava escrever, embora tivesse mais vontade do que talento, chamado $O$ imbecil. Neste, o que a personagem desejava criar era um "romance científico", baseado nas últimas teorias de psicologia mórbida, que apresentasse a saga da decadência da humanidade, "com os seus personagens, epilépticos uns, alcoólicos outros, histéricos e lipemaníacos alguns" (p. 64). Por meio dessa descrição do que deveria ser seu romance, podemos imaginar a influência de Zola e de seu método experimental sobre a inspiração artística de Juca, assim como sobre a do próprio Zeferino Brazil. Para Malcolm Bradbury e James McFarlane, uma das questóes em torno do modernismo seria se o naturalismo de Zola poderia ser considerado uma de suas autênticas manifestações ou não. Segundo os autores, "não restam dúvidas de que Zola, ao afirmar ser necessário nomear e divulgar sua tendência ${ }^{6}$, dar-lhe um programa e um manifesto enquanto princípio foi um componente essencial do moderno, integrante essencial de sua coesão e evolução" (BRADBURY; McFARLANE, 1998, p. 154).

\footnotetext{
${ }^{6}$ Referem-se à discussão entre Zola e Flaubert a respeito da utilização do nome "naturalismo", em que Zola posicionou-se favorável a nomear os movimentos de renovação estética a fim de que o público pudesse distingui-los como novidades.
} 
O que se observa na cidade de Porto Alegre entre o fim do século XIX e o início do século XX é a percepção de uma mudança, em primeiro lugar, nas formas de escrita, em direção a uma narrativa muitas vezes reconhecida como indecente, ou imoral, em última instância, a uma narrativa "espanta-burguês" comprometida com a transformação dos ideais de beleza clássicos. Em segundo lugar, a essas mutaçóes narrativas estavam associadas alteraçóes no estilo de vida do artista, conforme se demonstrou em relação ao estilo de vida boêmio. Além da percepção dessas mudanças, Zeferino Brazil e Marcelo Gama também incorporaram conjuntos de práticas que podemos definir, grosso modo, como boêmias, em suas próprias vidas. Tais reformulações, se não convertem, de imediato, a literatura que produziram em uma literatura moderna, criaram condiçôes para os jovens literatos que com eles conviveram de repensar sua produção artística.

A ideia de que haveria manifestaçôes externas, observáveis, do que ia no interior dos seres humanos, não era, obviamente, uma ideia original de Zeferino Brazil ou de Marcelo Gama, nem tampouco tratava-se de algo puramente relacionado com a literatura ou com a vida literária. De fato, as ideias que circulavam a esse respeito no que se refere à "genialidade" artística, sobretudo naquele momento histórico, derivavam do italiano Cesare Lombroso. Autor de $O$ homem criminoso, talvez sua obra mais conhecida, na qual indicava maneiras para reconhecer indivíduos criminosos ou predispostos a tendências criminosas, dentre as quais figuravam os formatos dos narizes ou a presença de tatuagens, Lombroso também escreveu $O$ homem de gênio, em que indicava características físicas e psicológicas dos artistas. As semelhanças entre ambos, o homem criminoso e o homem de gênio, às vezes são surpreendentes. São nessas obras que Juca se baseia para pensar a si mesmo e são nessas que encontra indícios de sua genialidade. Em certo momento, diz a Alberto:

- O pior é que estou seriamente enfermo, filho. Tenho tido ultimamente alucinaçôes pavorosas. - É sinal de gênio, Juca. Baudelaire, Flaubert, Gerard de Nerval, Schopenhauer e Poe foram alucinados.

Ele sorriu docemente. $\mathrm{O}$ Alberto não lhe contava novidade alguma. $\mathrm{O}$ Juca decerto não era um ser equilibrado. Não se confundia com o comum dos 'rapazes de talento'. Tinha esquisitices, ideias bizarras, acessos histéricos, visões surpreendentes. E isto não podia ser senão a epilepsia do gênio (BRAZIL, 1975 [1900], p. 95).

Não há dúvidas de que o texto de Brazil tem um caráter satírico, atuando com a intenção de demonstrar a farsa de certos "artistas" que não apresentam nenhuma produção, muito embora reivindiquem sua posiçáo com base sobretudo em suas práticas e naquilo que lhes ia "na alma", na semelhança real ou imaginada em relação aos escritores admirados. Além disso, o trecho citado tem a virtude de nos apresentar, mais uma vez, aos nomes daqueles considerados "artistas de gênio", quase como uma variação para os "artistas de verdade". 
Nesse sentido, a própria ideia de literato se associa à ideia de artista, na medida em que o escritor é o produtor de certo tipo de obra de arte; e o artista passa a figurar como alguém que, com sua arte, promove rupturas em vez de consensos. A vida deste também estava cercada de outras construçóes que compunham um "mito", uma ideia composta a partir dos relatos das vidas dos principais escritores admirados, além de seus romances e poesias. As drogas e a arte, assim, parecem ser um encontro constante:

- O chá é a bebida estética, por excelência - afirmou o romancista [Juca].

- Prefiro o café! - replicou o poeta. Como excitante é melhor. Rousseau embriagava-se com café.

- Mas o chá, em porcelana leve, faz pensar leve. É ao chá que eu devo os períodos mais sonoros de minha prosa. Não uso nem quero outro excitante. Haller e Gautier engoliam enormes doses de ópio: a mim o chá verde faz-me o mesmo efeito da morfina usada em injeçôes hipodérmicas (p. 97).

Do mesmo modo, quando Juca se dá conta de que é incapaz de uma produção constante e de qualidade, quando o tempo passa e suas páginas continuam em branco, ele

[...] lembrou-se de procurar um estimulante no álcool.

[...] Passando do caso particular ao geral, o Juca lembrou-se da multidão de artistas, poetas, romancistas, conteurs, músicos, que só se inspiravam no álcool, e que ao vinho ou ao absinto deviam a longa série de suas obras imortais. Eram Kleist, Musset, Byron, Gerard de Nerval, Murger, Lo-Tai-Ké (que morreu de asfixia alcoólica), Mailath, Rovain, Praga, Baudelaire, Poe (morto de delirium-tremens), Southey, Hoffmann, Cardan e Swift, que andava caindo pelas tavernas de Londres. E ainda outros, cujos nomes não tinha de memória, mas que já estavam citados no Homem de gênio (p. 118).

Assim como as drogas aparecem sendo consumidas por seus personagens, o próprio Brazil teve graves problemas com o alcoolismo, depois relatados em um romance de 1922, intitulado Meio. Outros de seus livros, como é o caso de Visão do ópio, de 1906, também retomam essa sorte de referência. No caso deste último, de poesias, também percebemos inúmeras formas de alusão à poesia de Baudelaire e de Edgar Allan Poe. Na primeira parte desse livro, temos um diálogo entre Satânio, Délio e Artêmio. Eles estâo no "gabinete fantástico de Satânio". Neste, as paredes são negras e há nelas quadros sombrios, onde se veem as torturas do Inferno, de Dante. Há ainda "armas exóticas" e "caveiras tétricas". E, num armário de vidro, "o esqueleto da primeira amante de Satânio". A descriçáo pretende aterrorizar o leitor, criar um clima de pavor. Os três bebem em taças feitas com crânios humanos. O diálogo travado em versos entre os três amigos denota que havia divergências acerca do 
estilo de verso mais adequado para descrever o mundo, alguns optando pela "escola romântica", outros rompendo com esta. A opçáo pela adesáo ou pelo rompimento aponta para uma relação com o modo de perceber a realidade.

A segunda parte é composta em torno do trabalho de Délio em seu quarto, descrito como um "quarto de poeta e boêmio". Vale a pena conhecer a descrição completa do que se esperava de um quarto de poeta e boêmio: "Mobiliário simples. Livros em desordem. Revistas e jornais. Ilustraçôes berrantes. Retratos e bustos de poetas célebres. É de manhã. Délio trabalha, inclinado sobre a secretária, visivelmente enervado" (BRAZIL, 1974 [1906], p. 15). O poeta, cheio de spleen, se deixa adormecer e, no sonho, encontra sua musa, uma visão ideal que deseja se entregar a ele. O rapaz descreve a si mesmo como alguém que "tem acessos de louco e terrores noturnos" e que deseja "fugir da multidáo". Bebe gotas de ópio. A musa, por sua vez, nomeada "Flor de Lis", também apresenta um olhar sobre ele de acordo com a visão da boêmia fin-de-siècle:

Talvez te venha a amar... Sei que bardos perfeitos

Não há, que todos são escravos das nevroses,

De vícios ancestrais, da degenerescência...

Mas, em tempos assim, de histerias e hipnoses,

Não cabe a perfeição na humilde, humana essência.

(BRAZIL, 1974 [1906], p. 19)

O poeta sofreria "alucinadamente, de uma psicopatia estranha e singular" em seu "cérebro doente” (p. 19). Essa visão, expressa tanto nas suas próprias palavras quanto nas da musa, está de acordo com a concepção que se tinha daqueles que escreviam poemas, na boêmia do fin-de-siècle, como um doente, um louco, o homem de gênio e o homem anormal estando separados por uma linha tênue. Até o fim, o grande poema de Brazil, com cinco partes no total, é marcado pelos versos macabros, que falam em neurastenia e na esperança na morte, além de alguns versos a respeito da vida na cidade moderna, seu cotidiano, as pessoas que passam. A melancolia dá a tônica da poesia, repleta de personagens como o "louco", o "diabo" e a "louca". Essa literatura das nevroses, da loucura, da melancolia e da morte poderia ser facilmente caracterizada como literatura decadente ou da decadência. Para Claudio Iglesias (2014, p. 13),

o decadentismo equipara o texto literário a um tóxico, um discurso cujo vigor está em sua capacidade de corromper. Des Esseintes, o herói de À rebours [refere-se ao romance de JorisKarl Huysmans], ordena sua biblioteca em função de uma tradição até então passada por alto, e na qual não há lugar para os clássicos: a dos nevrosés, os espíritos exangues e afinados cujas patologias nervosas, cheias de matizes individuais e sobressaltos, encarnam um estilo.

\footnotetext{
${ }^{7}$ No original: “[...] el decadentismo equipara el texto literario con un tóxico, un discurso cuyo vigor está en su capacidad de corromper. Des Esseintes, el héroe de $\grave{A}$ rebours, ordena su biblioteca en función de una
} 
As características da literatura decadente parecem muito bem expressas tanto na obra de Zeferino Brazil quanto nas referências que ele associa a seus personagens. O próprio Juca, como se disse, também possuía uma estante de livros, como Des Esseintes, organizada segundo a "periculosidade" dos autores, estando a última prateleira, a de Zola, proibida a Etelvina. Para Mary Gluck (2005), de fato, o romance de Huysmans, $\grave{A}$ rebours, teria quase sozinho criado a imagem do artista moderno até o fim do século XIX. Tal figuração seria precisamente a do decadente, "largamente retratado como o produto neurastênico de uma civilizaçáo envelhecida, que alcançou um estágio de desenvolvimento análogo àquele do Império Romano em seu declínio" (GLUCK, 2005, Kindle Edition. loc. 1260). ${ }^{8}$ Do mesmo modo, esse estilo de vida que podemos associar à boêmia decadente do fim do século XIX, também estava expresso em muitas das açôes de escritores como Zeferino Brazil e Marcelo Gama. Algumas dessas atitudes, bem como seus próprios livros, foram excepcionalmente formativos para os literatos mais jovens no início de suas carreiras. Um desses literatos iniciantes, Álvaro Moreyra, descreve em suas memórias como foi a reação de Marcelo Gama diante da recusa de um jornal em publicar alguns de seus versos, posteriormente reunidos num volume intitulado Noites de insônia:

Uma noite, o diretor de um jornal lhe recusou a publicação de uns versos; achava-os muito 'avançados'. Marcelo saiu do jornal, procurou os amigos jovens: - Preciso de todos. - Todos estavam decididos. No momento, eram quatro. Tomaram um carro juntos. - Vá pela Rua da Azenha. - Na ladeira do cemitério, mandou parar. - Venham. - Foram, ladeira acima. Que seria? Para que Marcelo os levara, a tais horas, para tal lugar? Marcelo caminhou até o portão, gritou: - Mortos! Mortos, os vivos não querem ouvir o que lhes digo! Venho dizer a vocês! - E disse os versos recusados, que mais tarde ampliou na Noite de insônia. De volta, a pé, os amigos, entusiasmados, elogiavam os versos, punham Marcelo no mais alto da admiração. E Marcelo explicou: - Eu trouxe vocês porque, no fundo, também não tenho muita confiança nos mortos... (MOREYRA, 1909, p. 32).

Assim, as referências decadentes de Zeferino Brazil e de Marcelo Gama criaram uma tradição literária a ser seguida pelos jovens escritores, que os admiravam e os tomavam como referência. Muito embora tal tradição não fosse uma particularidade rio-grandense, uma vez que existia ao redor do mundo com muito poucas modificaçôes, foi o contexto imediato de sua apropriação pelos "mestres" Brazil e Gama que os pôs em contato com a vida literária e com sua arte de viver.

tradición hasta entonces pasada por alto, y en la que no hay lugar para los clásicos: la de los névrosés, los espíritus exangües y afinados cuyas patologías nerviosas, llenas de matices individuales y sobresaltos, encarna un estilo".

${ }^{8}$ No original: "[...] widely depicted as the neurasthenic product of an aging civilization, which had reached a stage of development analogous to that of the Roman Empire in its decline". 
III.

Álvaro Moreyra nasceu em Porto Alegre no ano de 1888. Foi lá também que publicou seu primeiro livro, Degenerada (poema de um doudo), de 1909. Ele lembrou, anos depois, os tempos de juventude na cidade natal, quando se reunia com um grupo de sete amigos artistas na Praça da Misericórdia, onde passavam "todas as noites e todas as estaçôes" (MOREYRA, 1909, p. 42). Seus amigos, Eduardo Guimaraens, Felipe d'Oliveira, Homero Prates, Carlos de Azevedo, Antonius e Francisco Barreto, não permaneceram próximos a ele no decorrer dos anos, e alguns nem sequer se mantiveram táo próximos da literatura. Quando Moreyra seguiu para o Rio de Janeiro, provavelmente no ano de 1909, foi com Felipe d'Oliveira, e Homero Prates os acompanhou algum tempo depois. Mesmo em Porto Alegre, Eduardo Guimaraens enviava aos amigos contribuiçóes literárias, assim como Antonius Barreto também mandava seus desenhos. Francisco Barreto e Carlos de Azevedo, por sua vez, separaram-se de vez do grupo e da poesia.

Mencionamos o grupo como um todo porque ele parece ter tido uma importância grande na formaçáo literária de cada um de seus componentes. Eduardo Guimaraens, por exemplo, fez questáo de demarcar as características de cada um deles num poema denominado "O registro da plêiade", de 1909, nos tempos da Praça da Misericórdia. Embora um pouco longo, é imprescindível que o poema apareça completo:

\section{O REGISTRO DA PLÊIADE}

Nós somos três, três, três...

Trio dos jacarés

\section{Homero Prates}

Este é um pontifex maximus do verso!

Mestre do ritmo eril, o sonoro universo

Do seu rimário dá-nos mil exemplos:

E os seus poemas sagrados

Visam, aos nossos olhos deslumbrados,

Numa solenidade hierática de templos.

II. Felipe d'Oliveira

Este pode morrer quando quiser: de um poema

Que o seu estro trabalha, - eternamente

Há de ficar, dos tempos do destino,

O seu nome elevado a vitória suprema, 
Um verso alexandrino

"Os candelabros reais dos paços do nascente"

III. Francisco Barreto

Este não é da lira... mas, no entanto,

É um artista, também: que brilhe e reze

Seu nome, aqui, é natural portanto...

- Ah! Só tem um defeito, por enquanto:

Ter as mesmas feições de Afonso XIII

IV. Álvaro Moreyra

Este vem logo após o XIII real, na blague

Do número do agouro, e que os aldeóes assombra;

Vêde-o: é o mais conhecido e atacado dos sete:

E para que da crítica o estilete,

Definitivamente, o sangre e espete e esmague,

Vai-nos mostrar, por uma sexta-feira,

A claridade estética da sombra!

V. Carlos Azevedo

Este que se registra, agora, não faz parte

Do círculo musal. - Mas que isto se registre:

As suas mãos possuem, por um milagre de arte,

Os dedos do velho Lizst!

VI. Antonius

Este é um fino bambu, que do Bois de Bologne

Foi arrancado; e agora, entre os sete, ei-lo aqui:

O crayon, que o semelha,

A mão, nervosamente, ardendo na centelha,

O tipo a D. Eurico, o jeito a Gavarni,

$\mathrm{E}$ a dizer, e a engrolar os versos da charoque,

Ou então, quando o quer: "j'comprrrrnd qu'l'chat a frrrappé Baudelaire!"

VII. Eduardo Guimaraens

Este, que fecha a comédia

E o mau Registro dos Sete,

Tem um livro e uma tragédia,

E é um mocinho que promete ${ }^{9}$

Esse grupo se organizou e se definiu por um conjunto de características, mais ou menos vagas, por um ethos que os unificava, para resgatamos as palavras de Raymond

\footnotetext{
${ }^{9}$ GUIMARAENS, Eduardo. O registro da plêiade. Doc. n. 2332. AMLB, Avulsos. Fundação Casa de Rui Barbosa. 1909.
} 
Williams. No ano em que o poema foi escrito, 1909, Eduardo Guimaraens definia a si e a seus amigos sobretudo como um grupo de "artistas", pois são características ligadas ao universo da arte e da literatura, bem como a uma cultura francófila (o Bois de Bologne, o poeta Baudelaire e o modo de falar de Antonius, carregado nos erres), aquilo que ele enfatiza como fragmentos das "personalidades" de cada um. Aqui, não interpretamos os interesses associados a cada um deles a fenômenos particulares, restritos a certos indivíduos como expressão de seus "gênios", ou mesmo a esse grupo de escritores especificamente. Ao contrário, eles nos indicam uma cultura que extrapola aqueles indivíduos, valores e interesses socialmente disponíveis, revelando o que esse grupo buscava e com quem partilhava seus gostos. Em outras palavras, entendemos o gosto como uma instituição social, que demarca identidades e distinçôes (BOURDIEU, 2011). Portanto, é esse universo simbólico definido como "gosto", com marcas alegadamente individuais e únicas, que nos interessa, pois ele cria aproximaçôes e afastamentos entres os diferentes grupos de escritores. O encontro com certas "correntes literárias" não se dava exclusivamente pela apreciação estética, entendida como algo próximo do transcendente, mas respondia também a identidades sociais mais difusas, ligadas a esses universos simbólicos aos quais estavam conectados não somente a literatura, mas também as biografias dos escritores, suas viagens, seus modos de vida, seus estilos de vestir e de se comportar. Esses universos, que podemos definir amplamente como "cosmopolitismo", era o que possibilitava o elo dos escritores gaúchos, ou de alguns deles, do início do século XX, com o resto do mundo. Vinculando-se a essa "literatura mundial", nesse caso marcadamente francesa, compreendida, então, como "universal", os autores aqui analisados conseguiam articular narrativamente uma modernidade que náo podiam enxergar plenamente ao seu redor. Assim como os modernistas latino-americanos, estudados por Mariano Siskind, os escritores trabalhados neste artigo viam nessa rede discursiva, produzida sobretudo na Europa, uma possibilidade de integrar-se a uma comunidade mundial "organizada em torno de estéticas modernizantes" (SISKIND, 2016, p. 154). ${ }^{10}$

Dessa forma, ao observarmos a obra do grupo da Praça da Misericórdia, localizamos as características de sua produção capazes de garantir uma marca de grupo, aquilo que os unificava. Mesmo avessos a definiçôes por meio de escolas, algumas coisas se repetem na produção de todos eles, com sensíveis transformaçóes ao longo do tempo. Algumas dessas características estão presentes nos "noturnos"11, que se tornaram populares entre o fim do século XIX e início do XX, indicando o pertencimento a certo grupo de poetas, como Jules Laforgue e Paul Verlaine. Segundo William Sharpe (1992, p. 109),

\footnotetext{
${ }^{10}$ No original: "[...] organizada alrededor de estéticas modenizantes".

${ }^{11} \mathrm{O}$ termo advinha de composiçôes musicais de mesmo nome, como aquelas de Frédéric Chopin (que compôs 21 noturnos), mas também como as do húngaro Franz Liszt, associado a Carlos de Azevedo.
} 
depois de cerca de 1875 , aqueles que chamaram seus trabalhos "Noturnos" podiam se imaginar participando de uma tradição literária, musical ou artística, e talvez todas as três. A fluidez do termo sugere a fluidez das fronteiras artísticas que a maioria daqueles poetas e artistas se esforçaram por imaginar. ${ }^{12}$

Logo, os noturnos são um fenômeno social típico de uma época e podem nos auxiliar a compreender aspectos ainda pouco analisados dela. A esse fenômeno o grupo da Praça da Misericórdia se vinculou de variadas maneiras. Eduardo Guimaraens, por exemplo, publicou inúmeros "noturnos" ao longo de toda a sua carreira literária, intitulando-os de fato com esse nome. Já em seu primeiro livro, de 1908, ele escrevia:

A noite é triste como um sonho de assassino!

E alongando na treva o meu olhar extático

Penso no amor, penso na morte, no destino,

Em mim... E cada vez torno-me mais cismático

(GUIMARAENS, 1908, p. 31).

Em geral, os noturnos tendem a criar uma atmosfera mórbida, com referências, evidentemente, à noite, mas também caracterizados pela "onipresença de imagens da água, a preocupação com a morte e com cadáveres, sonhos e música, o senso de enormidade e a implacabilidade da cidade" (SHARPE, 1992, p. 108). Assim, o noturno poético expressaria a noite enquanto consequência do decair do dia, nascida do crepúsculo, mas também os sentimentos que se podem depreender dessa hora do dia: falta de esperança, impotência, doença e tudo o mais que possa, como a noite, ser ligado à decadência. Esse aspecto da unidade do grupo - os sentimentos de decadência - já se esboçava em Porto Alegre, quando da iniciação literária desses jovens, e naqueles escritores ligados à outra geração, renomados e conhecidos, como Marcelo Gama e Zeferino Brazil, que ofereciam o repertório estético (deles próprios e de outros escritores) às novas geraçóes. Desse modo, o que entendemos por tradição literária, neste artigo, é um contexto intelectual, que abarca as possibilidades de adesão estéticas oferecidas pela época e, em maior ou menor grau, pelo local onde a formação literária se deu. No caso aqui analisado, o grupo da Praça da Misericórdia, num primeiro momento, apresenta-se alinhado à tradição decadente, não promovendo, com ela, nenhuma ruptura significativa.

O primeiro livro de Álvaro Moreyra, Degenerada (poema de um doudo), também possui características que o vinculam a essa tradição literária, como se vê no pequeno texto de abertura:

\footnotetext{
${ }^{12}$ No original: "After about 1875, those who called their works "Nocturnes" could imagine themselves participating in a literary, musical, or artistic tradition, and perhaps all three. The fluidity of the term suggests the fluidity of artistic boundaries that most of these poets and artists strove to reexamine".
} 
Quando, ao tornar do cemitério, por aquele frígido crepúsculo de junho, atirei-me, roto e intoxicado, para cima da enxerga (sic), desmoronadamente, na safra emocional de uma visão de haxixe, o teu suave Espírito chegou, de muito longe, muito longe, envolto em hábitos azuis, e eu tive a revelação, Degenerada, deste Poema maldito! (MOREYRA, 1909, s/p.).

A referência ao poema maldito explicita o elo com o panteáo simbolista-decadente do fim de século francês, como Paul Verlaine, Tristan Corbière, Arthur Rimbaud, entre outros, mas a menção a uma musa que chega por meio de uma visão advinda do uso de substâncias psicotrópicas também nos remete ao Visão do ópio, de Zeferino Brazil. Em Casa desmoronada, segundo livro de Moreyra, também de 1909, o estilo de escrita soturno é igualmente mantido, com referências à noite, às sombras, ao luto e a todo um repertório decadente:

\section{Sexta-feira de Azar... Horas de Spleen... Abismos}

onde a Energia tomba... E sustos... e histerismos...

[...]

Abafo. Este calor é o evangelho da chuva.

Tomo um cigarro. Acendo. A retina viúva

Vai seguindo a fumaça...: aos fios se desdobra...

foge... desaparece, em meneios de cobra,

buscando-Te, talvez...

(MOREYRA, 1909, s/p.)

O primeiro livro de Felipe d'Oliveira, Vida extinta, é de 1911, quando o autor já se encontrava no Rio de Janeiro. Nele também é possível reconhecer alguns dos traços compartilhados pelos seus companheiros, como os ocasos, as olheiras e o outono. Em Homero Prates, igualmente, apesar das inúmeras diferenças formais e da presença de um repertório mais diversificado, também observamos, além dos temas ligados à morte e à noite, homenagens a escritores como Albert Samain e Edgar Allan Poe. O repertório decadente, típico dos "noturnos" e dos poetas malditos, esteve presente e os acompanhou, enquanto grupo, de formas distintas e com muitas transformaçôes, por toda a extensão de suas carreiras. De um modo geral, as temáticas que unificam esse grupo, assim, são aquelas que aparecem, grosso modo, na literatura do final do século francês, marcadas por um forte tom pessimista.

\section{IV.}

Quando chegam ao Rio de Janeiro, a partir do ano de 1909, os companheiros da Praça da Misericórdia se vinculam ao grupo de Mario Pederneiras, na revista Fon-Fon!. Entretanto, essa 
nova articulação com outros círculos literários, muito embora possibilite transformaçôes em suas escritas, não os fazem perder aquelas vinculaçóes estéticas da cidade natal, talvez inclusive por partilharem com os cariocas do grupo da Fon-Fon! muitos valores e elementos culturais. Além disso, como dissemos, mesmo aqueles que permaneceram na cidade de Porto Alegre, colaboravam, por meio dos amigos, com poesias ou desenhos que saíam também na revista.

Convidado para a Semana de Arte Moderna de 1922, Álvaro Moreyra não compareceu, ainda que tenha figurado na lista de palestrantes (COUTINHO, 1959, p. 76). Resistindo às classificaçôes, Moreyra nunca se definiu como "moderno" ou como "modernista" - "não pedi matrícula em nenhuma dessas escolas", dizia ele, "Na verdade, fui sempre um grande gazeteiro. Eis o que explica a 'minha escola' e o que deixo de mim" (MOREYRA, 2007 [1955], p. 38). Assim mesmo, por meio de sua literatura encontrou maneiras de se vincular a uma modernidade literária cosmopolita e informada por um universo simbólico que the permitia explorar sentimentos marcados pelas incertezas profundas do tempo em que vivia. O decadentismo foi uma daquelas tradiçôes muitas vezes apagadas ou silenciadas pelas posteriores construçóes sobre o passado, que conformou o modernismo brasileiro. $\mathrm{O}$ modo como se configura a dimensão do moderno aqui analisada, contudo, nos permite repensar as comuns oposiçôes que definem um pré-modernismo a partir da comparação com as vanguardas surgidas posteriormente. Sem procurar redefinir artificialmente hierarquias que o próprio espaço de criaçáo literária jamais tratou de firmar, isso sim, de elaborar uma perspectiva que vê as transformaçôes estéticas de modo processual, como alteraçôes que ocorrem antes nos próprios sujeitos que praticam literatura do que nos textos em si mesmos.

\section{Fonte documental}

GUIMARAENS, Eduardo. O registro da plêiade. Doc. n. 2332. AMLB, Avulsos. Fundação Casa de Rui Barbosa, 1909.

\section{Referências}

BOURDIEU, Pierre. As regras da arte: gênese e estrutura do campo literário. São Paulo: Companhia das Letras, 1996.

BOURDIEU, Pierre. A distinção: crítica social do julgamento. Porto Alegre: Zouk, 2011. BRADBURY, Malcolm; McFARLANE, James. Modernismo: guia geral. São Paulo: Companhia das Letras, 1998.

BRAZIL, Zeferino. Juca, o letrado. Porto Alegre: Divisão Cultural Sport Club Internacional, 1975 [1900]. 
BRAZIL, Zeferino. Visão do ópio. Porto Alegre: Divisão Cultural Sport Club Internacional, 1974 [1906].

BUTLER, Christopher. Modernism: a very short introduction. New York: Oxford University Press, 2010.

CALINESCU, Matei. Cinco caras de la modernidad: modernismo, vanguardia, decadência, kitsch, posmodernismo. Madri: Tecnos, 1991.

COUTINHO, Afrânio. A literatura no Brasil, v. III. Rio de Janeiro: Livraria São José, 1959. d'OLIVEIRA, Felipe. Vida extinta. Rio de Janeiro: Liga Marítima Brazileira, 1911.

DE LUCA, Tânia Regina. Prefácio. In: OLIVEIRA, Cláudia; VELLOSO, Monica Pimenta; LINS, Vera. O moderno em revistas: representaçôes do Rio de Janeiro de 1890 a 1930. Rio de Janeiro: Garamond, 2010.

GAMA, Marcelo. Via sacra. Porto Alegre: Tipografia de Octaviano Borba, 1902.

GAY, Peter. Modernismo: o fascínio da heresia: de Baudelaire a Beckett e mais um pouco. São Paulo: Companhia das Letras, 2009.

GLUCK, Mary. Popular Bohemia: modernism and urban culture in nineteenth-century Paris. Cambridge: Harvard University Press, 2005. Kindle Edition.

GOMES, Angela de Castro. Essa gente do Rio... modernismo e nacionalismo. Rio de Janeiro: Editora FGV, 1999.

GUIMARAENS, Eduardo. Caminho da vida. Porto Alegre: Livraria Americana, 1908.

IGLESIAS, Claudio. Prólogo. In: Antologia del decadentismo: perversión, neurastenia y anarquia en Francia. Buenos Aires: Caja Negra, 2014.

LEHAN, Richard. Literary modernism and beyond: the extend vision and the realms of the text. Baton Rouge: Lousiana State University Press, 2009.

LINS, Vera. Em revistas, o simbolismo e a virada do século. In: OLIVEIRA, Cláudia; VELLOSO, Monica Pimenta; LINS, Vera. O moderno em revistas: representaçôes do Rio de Janeiro de 1890 a 1930. Rio de Janeiro: Garamond, 2010.

MOREYRA, Álvaro. As amargas, não (lembranças). Rio de Janeiro: Academia Brasileira de Letras, 2007 [1955].

MOREYRA, Álvaro. Degenerada (poema de um doudo). Porto Alegre: Livraria Americana, 1909. RAINEY, Lawrence. Institutions of Modernism: literary elites \& public culture. New Haven/ London: Yale University Press, 1998.

SCARINCINI, Carlos. A gravura no Rio Grande do Sul (1900-1980). Porto Alegre: Mercado Aberto, 1982.

SCHOLES, Robert; WULFMAN, Clifford. Modernism in the Magazines. New Haven/ London: Yale University Press, 2010. 
SEIGEL, Jerrold. Paris boêmia: cultura, política e os limites da vida burguesa (1830-1930). Porto Alegre: L\&PM, 1986.

SHARPE, William. The nocturne in fin-de-siecle Paris. In: COOPER, Barbara; DONALDSON-EVANS, Mary (ed.). Modernity and Revolution in Late Nineteenth-Century France. Cranbury: Associated University Press, 1992.

SISKIND, Mariano. Deseos cosmopolitas: modernidad global y literatura mundial en América Latina. Buenos Aires: Fondo de Cultura Económica, 2016.

SOMIGLI, Luca. Legitimizing the Artist: manifesto writing and European modernism. Toronto: University of Toronto Press Incorporated, 2003.

VELlOSO, Monica Pimenta. História \& modernismo. Belo Horizonte: Autêntica, 2010.

VELLOSO, Monica Pimenta. Modernismo no Rio de Janeiro: turunas e quixotes. Rio de Janeiro: Editora da Fundaçấo Getúlio Vargas, 1996.

WILLIAMS, Raymond. A fração Bloomsbury. Plural, Sociologia, USP, São Paulo, n. 6, p. 139-168, 1999. 